\title{
Digital Technology and Rural Livelihood - A Study of Peasant Communities in Pru District
}

Abdul-Fatawu Shaibu, Zakaria Hudu, Mahunu Israel

Faculty of Agribusiness and Communication Sciences, University for Development Studies, Nyankpala Campus, Tamale Ghana

\begin{abstract}
There are a number of ways by which access to ICT can help boost economic activities of communities in a country with the mobile phone being the most common ICT tool especially in Sub Saharan Africa. To examine the impact of digital technology on rural livelihoods in the Pru district of the Brong Ahafo region of Ghana, a survey of 212 peasant farmers was conducted. The probit regression results indicate that, digital technology adoption is significantly influenced by age, cost and availability of the technology. Furthermore, digital technologies contribute to the improvement of rural livelihoods by expanding and strengthening social capital, increase people's ability to deal with emergencies and enhanced efficiency.
\end{abstract}

\section{Keywords}

Adoption, digital technology, livelihood, ICT, rural communities, peasant farmers, social capital.

Shaibu, A.-F., Hudu, Z. and Israel, M. (2018) "Digital Technology and Rural Livelihood - A Study of Peasant Communities in Pru District?", AGRIS on-line Papers in Economics and Informatics, Vol. 10, No. 4, pp. 71-78. ISSN 1804-1930. DOI 10.7160/aol.2018.100408.

\section{Introduction}

Many technologies can be used for human development particularly with regards to increased income and improvement in human health which permit people to participate more fully in their communities (United Nations Development Programme, 2001). Globally, there are evidences to show the impact of digital technology on development. Countries which were once "third world" are now rated "first world" due to their rapid development in technology. China, Sweden, Korea, Singapore are among many nations which have developed rapidly through technology (United Nations Development Programme, 2001).

Chambers (1997) stated that the rural development concept connotes overall development of rural areas with a view to improve the quality of life of rural people. It is a strategy to enable a specific group of people; mostly the poor, to gain for themselves and their families more of what they want and need. In this sense rural development is comprehensive in nature and encompasses development in agriculture, craft industries, socio-economic infrastructure, community services and human development (Chambers, 1997).
Digital technology is an important tool for empowering the poor. It contributed largely to Sweden's excellent infrastructure (Baller et al., 2016). In agriculture for example, Jensen (2007) seminal study of Kerala fishermen in India provided a clean identification of significant impacts of mobile phones on earnings, price volatility and waste management. A study of farmers conducted in Bangladesh, China, India, and Vietnam found that $80 \%$ of farmers in these countries owned mobile phones which they use to connect with agents and traders and to estimate market transactions (Reardon et al., 2010).

ICT infrastructure in Ghana is progressing as compared to other low-income countries globally and above $1.1 \%$ average for the Sub Saharan Africa (World Bank, 2016). Cell phone penetration rate had increased to $80.5 \%$ in August 2011 (Akanlisikum et al., 2014). In 2010 mobile subscription rose from 21.2 million to 35.9 million by April 2017 representing 59\% increase in total subscription over the period. Ghana's total mobile data subscription at the end of December 2016 stood at 19.6 million (National Communication Authority, 2017). However, the digital gab between urban and rural Ghana is still very wide 
even though some initiatives have started to deal with the challenges. In 2009, Ghana's Ministry of Communication for example pursued a programme to provide one model Community Information Centre (CIC) in each of 230 constituencies of Ghana to benefit the peri-urban and rural communities to help bridge the digital gap. While Internet adoption is growing steadily in Accra and other major cities, there is virtually no connection in most parts of rural Ghana.

Theoretical and conceptual framework

The theoretical foundation of the study is Diffusion of Innovation (DOI). DOI is one of the oldest social science theories originated in communication to explain how over time, an idea or product gains momentum and diffuses through a specific population or a community (Rogers, 1983). Rogers, (2004) posited with the DOI theory that, a person moves from first knowing about a particular innovation which he describes as the 'knowledge stage' to forming an attitude about that innovation called the 'persuasion stage', to making a decision whether or not to use a particular innovation usually referred to as the 'decision stage' to using an innovation (implementation stage) and to finally deciding whether to continue using an innovation (confirmation stage).

Technologies play an important role in economic development. Adoption and diffusion of technology are two interrelated concepts; describing the decision to use or not and the spread of a given technology among economic units over a period of time. Innovation adoption is not also a one step process. Tt takes time to complete. First time adopters may continue or cease to use the new technology. The duration of adoption of a technology vary among economic units, regions and attributes of the technology itself. Therefore, adequate understanding of the process of technology adoption and its diffusion is necessary for designing effective programmes.

The objective of the paper is to assess the adoption level of digital technology by rural folks and its impact on livelihoods in the Pru District of the Brong Ahafo Region of Ghana.

\section{Materials and methods}

Method of analysis

This study employed a combination of regression model and descriptive statistics to investigate the impact of digital technology on livelihood activities of the people in the Pru District of the Brong Ahafo region of Ghana. Specifically, we used the probit model to investigate the factors that influence the adoption of digital technology by rural folks while descriptive statistics was used to assess its contribution to rural livelihood activities. The data for the study was collected using questionnaires and personal interviews

\section{Empirical model specification}

The probit model can be stated generally as;

$$
P_{i}=c+(1-c) F\left(Z_{i}\right)
$$

$P_{i}$ is the probability that the ith case experiences the event of interest. $Z_{i}$ is the value of the unobserved continuous variable for the ith case. $F$ is a link function, transforming $Z$ from real line into the $0-1$ interval, $c$ is the natural response rate. The natural response rate is the probability of getting a response with no dose, and is equivalent to the constant term in the OLS regression.

The probit model also assumes that $Z$ is linearly related to the predictors by the function

$Z_{i}=b_{0}+b_{1} x_{11}+b_{2} x_{12}+\ldots+b_{k} x_{i k}$

Since $Z$ cannot be observed, we must relate the explanatory variables to the probability of interest by substituting for $Z$ in the equation for probability. This produces

$P_{1}=c+(1-c) F\left(b_{0}+b_{1} x_{11}+b_{2} x_{12}+\ldots+b_{k} x_{i k}\right)$

However, the empirical model for this study is stated as;

$$
\begin{aligned}
P(\text { Adopt }) & =\beta_{0}+\beta_{1} X_{1}+\beta_{2} X_{2}+\beta_{3} X_{3}+\beta_{4} X_{4} \\
& +\beta_{5} X_{5}+\beta_{6} X_{6}+\beta_{7} X_{7}+\beta_{8} X_{8}+u
\end{aligned}
$$

Where;

$P$ (Adpt) is probability of adoption which is a dummy variable ( 1 if the rural folk adopts digital technology and 0 is otherwise).

The $\beta_{s}$ are the unknown coefficients to be estimated $X$ is a vector of independent variables, which include $\left(X_{1}\right)$-age, $\left(X_{2}\right)$-gender, $\left(X_{3}\right)$-educational background, $\left(X_{4}\right)$ - total expenditure on digital technology usage, $\left(X_{5}\right)$-cost of digital equipment, $\left(X_{0}\right)$ attitude towards $I C T$, $\left(X_{7}\right)$-proximity to the nearest town or city and $\mu$ is the error term. 


\section{Hypotheses and description of variables}

The hypothesis of our study is that adoption of digital technology is significantly influenced by personal, environmental and socio economic factors.

Adoption of digital technology is the dependent variable and it is represented by 1 if the rural folks adopt and 0 is otherwise. The independent variables that influence the adoption of digital technology were selected based on literature and personal experience.

- Age (AGE): It is a continuous variable and measured in years. Literature reveals that young people are more flexible in deciding for change than aged people (Motamed and Singh, 2003). Therefore, we anticipate a negative relationship between age and adoption. Thus young people will adopt digital technology more than the older people.

- Gender(GENDER): This is a dummy variable measured by 1 if the respondent is male and 0 if the respondent is a female. The gender of a respondent in the rural setting is more likely to affect the decision to adopt the digital technology. In a study of 'Gender Differences in Technology Adoption and Welfare Impact among Nigerian Farming Households, Adekemi (2014) observed that adoption level was $26 \%$ higher among male than their female counterparts. Our anticipation is that males will adopt digital technology more than the females.

- Educational background (EB): the use of digital technology involves technical knowhow. Feder et al. (1985) noted that education improves the decision making process and influence the level and or composition of other inputs. Education increases the understanding and application of the technology. This variable was measured based upon whether or not the respondent had formal education. The dummy variable was measured by 1 if the respondent had any formal education (from primary to tertiary level) and 0 is otherwise. The expected sign of this variable is positive. Thus farmers with some level of formal education are likely to be more adoptive than those without any formal educational background

- Total expenditure (TEXn): It is a continuous variable and measured by the total amount of money the respondent spends on the use of digital technology. The expenses covered the cost of repairs, airtime, electricity bill among others. We expect a negative sign for this variable.

- Total cost of digital technology (TCTD): it is a continuous variable and measured by the total amount of money the respondent spends in the acquisition of the technology device. The cost of the digital technology is hypothesised to negatively affect the decision to adopt.

- Attitude towards ICT(ATTU): this is a dummy variable and a combined measure of respondents' perception of the usefulness of ICT and the ease with which it can be used. One (1) represents a respondent who believed that digital technology is useful and easy to use and 0 is otherwise. The apriori expectation for this variable is positive. In their investigation of Factors Affecting ICT Adoption in Rural Areas in Iran Vosough et al (2015) reported that households' attitudes towards ICT, compatibility and contact with agricultural extension agents are significant determinants for ICT adoption.

- Proximity (PROXIMITYN): it is a continuous variable and denotes the distance between the rural community and the nearest town or city where digital technology is sold. It was hypothesized that the closer the community to a city or town where the digital technology could be acquired, the more likely it is for the respondent to adopt.

The study area

Pru District is one of the 22 districts of the Brong Ahafo Region of Ghana. The district lies between longitude $0 * 30$ " $\mathrm{W}$ and $1 * 26$ " $\mathrm{W}$ and latitudes $7 * 50$ " $\mathrm{N}$ and $8 * 22 \mathrm{~N}$. The district experiences tropical continental or interior savannah type of climate with mean annual temperature ranging between $26.50^{\circ} \mathrm{C}$ and $27.20^{\circ} \mathrm{C}$. It also has double maxima rainfall pattern with annual rainfall ranging between $800 \mathrm{~mm}$ to $1400 \mathrm{~mm}$ hence their activities are dominated by fishing and farming. It shares boundaries with seven (7) other Districts, namely, East Gonja to the North of the Northern Region, Sene East and West Districts to the East, Nkoranza and Atebubu-Amantin to the South and Kintampo North and South Districts to the West, all in the Brong Ahafo Region. The District of Pru covers an area of $3220 . \mathrm{kmsq}$ and the capital is Yeji. The population of Pru District is 129,248 representing $5.6 \%$ 
of the Region's total population. The District has a household population of 127,069 with a total number of 22,579 households. Of the population of 12 years and above, $20 \%$ have mobile phones and only $0.5 \%$ of the total households in the district have access to internet facility while $0.8 \%$ own desktop or laptop computers (GSS, 2014).

\section{Sampling procedure}

Sample size can be determined by the application of one of several mathematical formulae. For populations that are large, the Cochran (1977) equation yields a representative sample for proportions. With a cross - sectional design, multi- stage sample technique was employed. At the first stage, purposive sampling was employed to select the 5 peasant communities. These are Sawaba, Daman Nkwata, Zambrama, Abease, and Beposo. These communities have relatively larger populations in the district. In the second stage we used the Yamane (1967) formula to determine a representative sample for the populations of the study communities. However, these samples were further scaled down through the Fisher et al. (1991) method taking into consideration the maximum budget, time limit and nature of the study. According to Yamane (1967), for a 95\% confidence level and $p=0.5$, size of the sample should be estimated as;

$$
\mathrm{n}=\frac{N}{1+N\left(e^{2}\right)}
$$

where, $\mathbf{n}$ is the sample size, $\boldsymbol{N}$ is the population size and $\mathbf{e}$ is the level of precision.

The sample size based on simplified formula from Fisher et al. (1991) is stated as;

$\mathbf{n}=\frac{(1.96)^{1} * p q}{d^{2}}$

where $\mathbf{n}$ is the sample size, $\boldsymbol{d}$ is the desired level of precision (which is $95 \%$, p0 is the proportion of the population with a key characteristic and $\boldsymbol{q}$ is $1-q$. Using the population of the study communities in Table 1 below, $\boldsymbol{p}$ is calculated as

$$
\begin{aligned}
& \boldsymbol{p}=\frac{21,305}{129,248} \times 100=16.5 \%=0.165 \\
& \text { and } q \text { is }(1-p)=1-0.165=0.835 \\
& \text { Therefore, } n=\frac{(1.96)^{2}(0.165)(0.835)}{(0.05)^{2}} \\
& =211.6 \\
& \cong 212
\end{aligned}
$$

This sample was divided equally among the five selected communities as shown in Table 1 .

\begin{tabular}{lccc}
\hline Community & Population & $\begin{array}{c}\text { Sample Size } \\
\text { (by Yamane } \\
\text { Formula) }\end{array}$ & $\begin{array}{c}\text { Selected Sample } \\
\text { (by Fisher } \\
\text { formula) }\end{array}$ \\
\hline Beposo & 3112 & 354 & 42 \\
Zambrama & 5182 & 371.3 & 42 \\
Sawaba & 4850 & 369.52 & 42 \\
Abease & 4117 & 364.6 & 42 \\
Daman Nkwata & 4044 & 363.9 & 42 \\
\hline Total & $\mathbf{2 1 ~ 3 0 5}$ & $\mathbf{1 8 2 3 . 3 2}$ & $\mathbf{2 1 2}$ \\
\hline
\end{tabular}

Source: authors' elaboration 2017

Table 1: Targeted population of the study area and selected sample.

\section{Results and discussions}

This section presents the results, discussion and findings of the study. It highlights the socio economic characteristics of respondents, factors influencing adoption of digital technologies and the impact of adoption on livelihood activities.

\section{Demographic characteristic of respondents}

From Table 2, it can be seen that $56 \%$ of respondents are male while $44 \%$ are female. Of the 212 respondents, about $58 \%$ are between the ages of 20 and 30 years while only $5.6 \%$ were 61 years and above, an indication of a growing population in the study area. About 56\% of the respondents have no formal education, while about $41 \%$ had attended school up to Senior High level and less than $1 \%$ had tertiary education. In terms of employment, about $48 \%$ are farmers while $38 \%$ are employed in the informal sector. The results also showed that $56.6 \%$ have access to mobile phones. Those who own both mobile phone and digital TV are $16 \%$ while $0.5 \%$ of the respondents have access to mobile phone and personal computer only. Overall less than $1 \%$ of the study population have access to all the three components of digital technology while $29.7 \%$ do not have access to any.

\begin{tabular}{llll}
\hline Variable & Response category & Frequency & Percent \\
\hline Gender & Male & 104 & 56 \\
& Female & 98 & 44 \\
& Total & 212 & 100 \\
Age & $20-30$ yrs & 124 & 58.5 \\
& $31-40$ yrs & 40 & 18.9 \\
& $41-50$ yrs & 19 & 8.9 \\
& $51-60$ yrs & 17 & 8 \\
& $60 y r s \&$ above & 12 & 5.6 \\
& Total & 212 & 100
\end{tabular}

Source: authors' elaboration 2017

Table 2: Demographic characteristics of respondent $(\mathrm{N}=212)$ (to be continued). 


\begin{tabular}{llll}
\hline Variable & Response category & Frequency & Percent \\
Education & Non formal & 120 & 56.6 \\
& primary & 33 & 15.6 \\
& JHS & 28 & 13.2 \\
& SHS & 30 & 14.2 \\
& Tertiary & 1 & 0.5 \\
& Total & 212 & 100 \\
& Formal sector & 20 & 9.5 \\
& informal & 80 & 37.7 \\
& farming & 102 & 48.1 \\
& Apprentership & 10 & 5 \\
& Total & 212 & 100 \\
& Mobile phone & 120 & 56.6 \\
& Mobile phone \& digital TV & 34 & 16 \\
& Mobile phone \& pc & 1 & 0.5 \\
& Mobile phone, digital TV & 1 & 0.5 \\
& \& PC & & 26.4 \\
\hline & None & 56 & $\mathbf{1 0 0}$ \\
\hline & Total & $\mathbf{2 1 2}$ & \\
\hline
\end{tabular}

Source: authors' elaboration 2017

Table 2: Demographic characteristics of respondent $(\mathrm{N}=212)$ (continuation)

Factors influencing adoption of digital technologies by rural folks

The probit model was used to analyse the factors influencing adoption of digital technology in the study communities and the results are presented in Table 3. Overall the estimated model was significant at $1 \%$ level. The likelihood ratio was $37.21(\mathrm{p}<0.0000)$. The pseudo $\mathrm{R}$ - square value of 0.7753 and the model correctly predicted $77.53 \%$ of the sample. The results show that certain socio demographic and economic factors are important in explaining adoption of digital technology by rural folks.

The explanatory variables that fit the model are age, expenses on use of digital technology, cost of digital technology, and proximity to the nearest town or city where digital technologies can be acquired. These were found to be significant as hypothesized. Gender, educational background, and whether or not the respondent had ever lived in a city were insignificant.

Age of rural folks were found to be significant at $1 \%$ and negatively related to the adoption of digital technology by rural folks. The negative coefficient effect means that, younger folks had a higher probability of adopting digital technology than the older folks. This result is supported by the findings of Motamed and Singh, (2003) that youthful exuberance is an important aspect of decision making in the adoption process.

As shown in Table 3, the total expenditure on the use of digital technology were found to be significant at $5 \%$. The negative sign implies that, the higher the expenditure on the use of digital technology, the less likely it is for the rural folks to adopt. Ali et al. (2015) also confirmed that transportation and other related cost negatively affects the returns of adoption in their study of the Impact of transport cost on technology adoption in Nigeria. The total cost of digital technology was also found to be significant at $1 \%$. Thus increment in the cost of using digital technology which include maintenance, power and call credit, significantly influence the people of Pru district to adopt digital technology in their livelihood activities.

Proximity to the nearest city or town was found to be significant at $1 \%$ and positively related to adoption of digital technology by rural folks. The positive coefficient means that the closeness of the community to the nearest city where digital technologies are found significantly increase the probability of adoption.

\begin{tabular}{lcccc}
\hline Adopters & Coefficient & Robust Coef. Std. Err & P $>\mathbf{z}$ & Marginal effect \\
\hline GENDER & -0.503 & 0.407 & 0.217 & -0.056 \\
AGE & -0.594 & 0.192 & $0.002 * * *$ & -0.058 \\
EB & -0.135 & 0.387 & 0.728 & -0.013 \\
TEXn & 0.012 & 0.006 & $0.045^{* *}$ & 0.001 \\
TCDT & 0.019 & 0.003 & $0.000 * * *$ & 0.002 \\
CITY & 0.014 & 0.515 & 0.978 & 0.001 \\
PROXIMITYn & -0.097 & 0.024 & $0.000 * * *$ & -0.009 \\
Constant & -1.706 & 0.852 & 0.045 & - \\
\hline
\end{tabular}

Note: Dependent variable: rural folks adopt digital technology or not $(1=$ Yes, $0=$ No);

$* * *$ significant at $1 \% ; * *$ significant at $5 \%$

Wald $\operatorname{chi}^{2}(7)=37.21 ;$ Prob $>$ chi $^{2}=0.0000$

Source: authors' elaboration 2017

Table 3: The probit model explaining adoption of digital technologies. 
Contributions of digital technology to livelihood activities

Table 4 below shows the contribution of digital technology to the livelihood activities of rural folks in the Pru District. We used mean scores to measure the perception of respondents about the impact of digital on their livelihood. The livelihood activities (LA) measured are social capital (S), human capital (H), vulnerability (V), financial capital (F), processes and institutions and policies (PIP). These variables were measured against certain key aspects of livelihood in relation to how digital technology has improved their status and these include relationship with friends and relatives, efficiency in daily activities, dealing with emergencies, membership in groups and networking, status of culture, communication with government departments and agencies, general neighbourhood security, business activities, social functions, household income and money transfers.

Social networking and relationship building were the most important benefits of using digital technology as $66.7 \%$ of respondents indicated that DT had either improved or greatly improved their relationships and contacts with friends and relatives. A mean score of 3.3 on a scale of 1 to 4 indicates highly positive responses. The results further revealed that social benefits of digital technology were also linked to reduced physical visits and decreased cost of travel. These findings suggest that digital technologies enabled rural folks to overcome vulnerabilities related to social exclusion apart from the important role it played in saving time and cost associated with travel.

The link between digital technology usage and efficiency of daily activities also produced highly positive response, with a mean score of 3.1 Overall, $61.7 \%$ of the respondents admitted that the efficiency of their daily activities had either improved or greatly improved. These results tally with the opinions from the field interview in which participants reported that the use of digital technology had enabled them to do more livelihood activities efficiently which is a significant contribution to human capital. The use of digital technologies allows rural folks to engage in many activities, something that can be translated into improved income earning and cost savings.

Getting support during emergencies was also a significant contribution of digital technology to human security. With a mean score of 3.1 , more than half $(56.8 \%)$ of the respondents believed that digital technology enhanced their ability to deal with emergencies. In an interaction with the rural folks during the field survey, some respondents reported the important role of these technologies in contacting the Community-Based Health Planning and Services CHPS compound in the Pru District which is approximately (20) miles away from the sampled communities to address their health needs.

Digital technology has also contributed significantly to the general security in the neighborhood recording a mean score of 3.1 in the perception rating. During the field survey, a key informant in Beposo described how the mobile phone was used to communicate with neighbouring communities, leading to a joint effort to arrest armed robbers who had operated in the community. Most crimes were prevented and arrests made through the on time information delivery through the mobile phone.

Another significant area that is worth looking at, is the contribution of digital technologies to the business status of the rural folks. About 58.5\% approved of its usefulness to their businesses with a mean of 3.1. According to reports during the field survey, most of the respondents gave account of how digital technologies have reduced the cost of doing business. They now spend less on transportation, and go through less stress to find out the prices of products from distant markets. They are able to communicate with their business counterparts to effectively execute their transactions. Some of them access market information through the internet while others do money transfers through their smart phones.

Household income is a very vital component of financial capital. Results from the Table 4 shows that $57.7 \%$ of respondents reported that digital technology has significantly improved their household income. With a mean value of 3.1, digital technologies have had a positive impact on improving the financial capital of the rural folks. A study by Statistics New Zealand (2001) also suggest that households with more internet access are likely to increase their annual incomes five times more than household with less internet access.

The results also show that $51.3 \%$ of the total respondents believed digital technologies has improved their ability to do money transfers. In an interaction with the respondents during the field survey, most of the rural folks reported that digital technologies have made their financial transactions easier. They are able to send and receive money from their wards and business clients at any timer. The inconveniences associated with banking 


\begin{tabular}{|c|c|c|c|c|c|c|c|}
\hline \multirow[t]{2}{*}{ Livelihood aspect } & \multirow[b]{2}{*}{ LA } & \multirow[b]{2}{*}{$\mathbf{N}$} & \multicolumn{4}{|c|}{ Percentage } & \multirow[b]{2}{*}{ 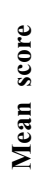 } \\
\hline & & & 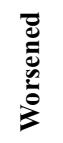 & 艺 & 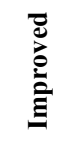 & 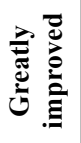 & \\
\hline Relationship/ Contacts With Friends And Relatives & $\mathrm{S}$ & 156 & 0 & 3.6 & 42.8 & 23.9 & 3.3 \\
\hline Efficiency In Daily Activities & $\mathrm{H}$ & 156 & 0 & 8.6 & 49.1 & 12.6 & 3.1 \\
\hline Help In Case Of Emergencies & $\mathrm{V}$ & 155 & 0 & 13.1 & 40.1 & 16.7 & 3.1 \\
\hline Membership In Groups And Networks & $\mathrm{S}$ & 156 & 0 & 20.7 & 45 & 4.5 & 2.8 \\
\hline Status Of Culture & $\mathrm{S}$ & 156 & 0.5 & 33.3 & 14 & 22.5 & 2.8 \\
\hline Communication With Government Departments & PIP & 156 & 0.9 & 50.9 & 17.1 & 1.4 & 2.3 \\
\hline General neighborhood Security & $\mathrm{V}$ & 156 & 3.2 & 14.4 & 39.2 & 13.1 & 3.1 \\
\hline Business Status & $\mathrm{F}$ & 155 & 0.9 & 9.9 & 45.9 & 12.6 & 3.1 \\
\hline Arrangement Of Social Functions & $\mathrm{S}$ & 156 & 0 & 20.7 & 45.5 & 4.1 & 2.8 \\
\hline Household Income & $\mathrm{F}$ & 156 & 0.9 & 11.7 & 31.1 & 26.6 & 3.1 \\
\hline Sending and receiving money & $\mathrm{F}$ & 155 & 0.5 & 18 & 31.5 & 19.8 & 3 \\
\hline
\end{tabular}

Note: $\mathrm{S}=$ social capital, $\mathrm{F}=$ financial capital, $\mathrm{H}=$ human capital, $\mathrm{V}=$ vulnerability, $\mathrm{P}=$ physical capital, $\mathrm{PIP}=$ Processes, Institutions and Policies Source

Source: authors' elaboration 2017

Table 4: Analysis of the impact of digital technologies on livelihood $(\mathrm{N}=212)$.

institutions according to the respondents have been minimized. A key informant at Beposo, who happens to be the 2015 District Best Farmer, reported how he used the Mobile Money system technologies to facilitate a quick transfer of money to his ward in the northern part of the Volta Region, who was at the verge of being prevented from taking an examination in school because she defaulted in paying on time.

\section{Conclusion}

The main objective of the study was to assess the adoption of digital technology by rural folks in the Pru district of the Brong Ahafo Region of the republic of Ghana, and its contribution to rural livelihoods. The literacy level in the study area is low. The factors affecting the adoption of digital technologies by the rural folks as revealed by the probit regression were age, cost of use and maintenance, price of the digital technologies, and proximity to the nearest town or city where the digital technologies are available for procurement. The results from the descriptive statistics on the contributions of digital technologies to livelihood activities revealed that contact with relations, family and friends were the most significant aspects of livelihood the people benefited from the adoption of digital technologies besides the help they get in cases of emergency, efficiency in daily activities, general neighborhood security, improved household income, improvement in business status, and the ease with which they do money transfers among relatives, friends and business associates.

Digital technology has proven to have immense contribution to social capital as the social relationships of the peasants in the study area had improved. However, the main challenge is poor telecommunication network. Therefore, the telecommunication networks can do more to extend their services to these deprived communities. Government policy should be put in place to ensure that digital technologies are more accessible and affordable to all, especially those in peasant communities. Talk tax and other communication levies should be reviewed downwards to reduce call cost.

Accessibility to digital technology devices had impacted negatively on peoples' adoption behaviour. The digital industry especially the telecommunication companies should make their products and services accessible to the peasant communities in the Pru District and Brong Ahafo Region in general. The cost on the use of digital technologies was significant at 5\%. Government subsidies should be given to these folks especially on electricity so as to reduce power expenditure and its related cost. 
Corresponding authors

Shaibu Abdul-Fatawu

Department of Communication Innovation and Technology-Faculty of Agribusiness and Communication Sciences, P. O. Box TL 1882, University for Development Studies, Nyankpala Campus, Tamale, Ghana Phone: (0233) 245735525,Email: fatash73@yahoo.ca; afshaibu@uds.edu.gh

\section{References}

[1] Akanlisikum, A., Aziale, L. and Asampana, I. (2014) "An Empirical Study on Mobile Phone Usage among Young Adults in Ghana: From the Viewpoint of University Students", International Journal of Computer Applications, Vol. 98, No. 5, pp. 15-21. ISSN 2250-1797. DOI 10.5120/17178-7273.

[2] Ali, R., Barra, A. F., Berg, C., Damania, R., Nash, J. and Russ, J. (2015) "Impact of Transport Cost on Technology Adoption", pp. 57-84. ISBN 978-1-4648-0654-4. DOI 10.1596/978-1-4648-0654-4_ch3.

[3] Chambers, R, (1997) Editorial: "Responsible Well-being: A Personal Agenda for Development", World Development Economic Forum, Vol. 25, No. 11, pp. 1743-1754. ISSN 0305-750X. DOI 10.1016/S0305-750X(97)10001-8.

[4] Cochran, W. G. (1977) "Sampling techniques", $3^{\text {rd }}$ ed. John Wiley \& Sons, New York, N.Y. ISBN 0-47 1-1 6240-X.

[5] Feder, G., Just, R. and Zilberman, D. (1985) "Adoption of Agricultural Innovations in Developing Countries: A Survey", Economic Development and Cultural Change. Vol. 33, No 2, pp. 255-298. E-ISSN 1539-2988, ISSN 0013-0079. DOI 10.1086/451461.

[6] Fisher, A. A., Laing, J. E., Stoeckel, J. E. and Townsend, J. W. (1991) "Handbook for Family Planning Operations Research Design", $2^{\text {nd }}$ ed., 43 p., Population Council, New York, USA. [Online]. Available: www.popcouncil.org [Accessed: 20 Sept. 2018].

[7] Jensen, R. (2007) "The Digital Provide: Information (Technology), Market Performance, and Welfare in the South Indian Fisheries Sector", The Quarterly Journal of Economics, Vol. 122, No. 3, pp. 879-924. E-ISSN 1531-4650, ISSN 0033-5533. DOI 10.1162/qjec.122.3.879.

[8] Motamed, M. K. and Singh, B. (2003) "Correlated of adoption of improved sericulture practices", Indian Journal of Extention Education, Vol. 39, No. (1\&2), pp. 51-57. ISSN 0972-2181.

[9] National Communication Authority (2017) "Industry Information - Telecom Subscriptions for July 2017", National Communications Authority, Airport City Accra, Ghana, September 29, 2017.

[10] Reardon, T., Timmer, P. C. and Minten, B. (2010) "Supermarket revolution in Asia and emerging development strategies to include small farmers", Proceedings of the National Academy of Sciences of the United States of America, Vol. 109, No. 31. pp. 12332-12337. DOI 10.1073/pnas. 1003160108.

[11] Rogers, E. M. (1983) "Diffusion of Innovations: Third Edition", The Free Press A Division of Macmillan Publishing Co., Inc. 866 Third Avenue, New York, N. Y. 10022. ISBN 0-02-926650-5.

[12] Rogers, E. M. (2004) "A Prospective and Retrospective Look at the Diffusion Model", Journal of Health Communication, Vol. 9, No.1, pp. 13-19. DOI 10.1080/10810730490271449.

[13] United Nations Development Programme (2001) "Human Development Report 2001- Making New Technologies Work for Human Development", Oxford University Press, Inc. 198 Madison Avenue, New York, New York. ISBN 0-19-521835-3

[14] Vosough, A., Niusha, E. and Akram, B. (2015) "Factors Affecting ICT Adoption in Rural Area: A Case Study of Rural Users in Iran", Research Journal of Fisheries and Hydrobiology, Vol. 10, No. 10, pp. 611-616. ISSN 1816-9112.

[15] World Bank (2016) “World Development Report 2016: Digital Dividends", Overview booklet, World Bank, Washington, DC. License: Creative Commons Attribution CC BY 3.0 IGO

[16] Yamane, T. (1967) "Statistics: An Introductory Analysis", $2^{\text {nd }}$ Ed., New York: Harper and Row. 